\title{
Surgical staging and prognosis in serous borderline ovarian tumours (BOT): A subanalysis of the AGO ROBOT study
}

F Trillsch ${ }^{1,33}$, S Mahner ${ }^{\star}, 1,33$, E Vettorazzi ${ }^{2}$, L Woelber ${ }^{1}$, A Reuss ${ }^{3}$, K Baumann $^{4}$, M-D Keyver-Paik ${ }^{5}$, U Canzler ${ }^{6}$, $\mathrm{K}$ Wollschlaeger ${ }^{7}$, D Forner ${ }^{8}$, J Pfisterer ${ }^{9,10}$, W Schroeder $^{11}$, K Muenstedt $^{12}$, B Richter ${ }^{13}$, C Fotopoulou $^{14}$, B Schmalfeldt ${ }^{15}$, A Burges ${ }^{16}$, N Ewald-Riegler ${ }^{17}$, N de Gregorio ${ }^{18}$, $\mathrm{F} \mathrm{Hilpert}^{19}$, T Fehm $^{20,21}$, W Meier ${ }^{22}$, P Hillemanns ${ }^{23}$, L Hanker ${ }^{24,25}$, A Hasenburg ${ }^{26}$, H-G Strauss ${ }^{27}$, M Hellriegel ${ }^{28}$, P Wimberger ${ }^{6,29}$, S Kommoss ${ }^{17,20}$, F Kommoss ${ }^{30}$, S Hauptmann ${ }^{27,31}$ and A du Bois ${ }^{32}$

${ }^{1}$ Universitaetsklinikum Hamburg-Eppendorf, Klinik und Poliklinik fuer Gynaekologie, Martinistr. 52, 20246 Hamburg, Germany; ${ }^{2}$ Universitaetsklinikum Hamburg-Eppendorf, Institut fuer Medizinische Biometrie und Epidemiologie, Martinistr. 52, 20246 Hamburg, Germany; ${ }^{3}$ Philipps-Universitaet Marburg, Koordinierungszentrum fuer Klinische Studien, Karl-von-Frisch-Str. 4, 35043 Marburg, Germany; ${ }^{4}$ Universitaetsklinikum Giessen u. Marburg GmbH, Klinik fuer Gynaekologie, Gyn. Endokrinologie und Onkologie, Baldingerstr., 35043 Marburg, Germany; ${ }^{5}$ Rheinische Friedrich-Wilhelms-Universitaet, Universitaets-Frauenklinik, Sigmund-Freud-Str. 25,53127 Bonn, Germany; ${ }^{6}$ Technische Universitaet Dresden, Klinik und Poliklinik fuer Frauenheilkunde und Geburtshilfe, Fetscherstr. 74,01307 Dresden, Germany; ${ }^{7}$ Universitaetsklinikum Magdeburg, Universitaets-Frauenklinik, Gerhart-Hauptmann-Str. 35, 39108 Magdeburg, Germany; ${ }^{8}$ SanaKlinikum Remscheid, Klinik fuer Frauenheilkunde und Geburtsmedizin, Burger Strasse 211, 42859 Remscheid, Germany; ${ }^{9}$ Staedtisches Klinikum Solingen gGmbH, Klinik fuer Gynaekologie und Geburtshilfe, Gotenstrasse 1, 42653 Solingen, Germany; ${ }^{10}$ Zentrum fuer Gynaekologische Onkologie, Herzog-Friedrich-Str. 21, 24103 Kiel, Germany; ${ }^{11}$ GYNAEKOLOGICUM Bremen, Schwachhauser Heerstrasse 367, 28211 Bremen, Germany; ${ }^{12}$ Universitaetsklinikum Giessen, Zentrum fuer Frauenheilkunde und Geburtshilfe, Klinikstrasse 33,35352 Giessen, Germany; ${ }^{13}$ Elblandkliniken Meissen-Radebeul GmbH \& Co. KG, Frauenklinik, Heinrich-Zille-Str. 13, 01445 Radebeul, Germany; ${ }^{14}$ Charité, Campus Virchow Klinikum, Frauenklinik, Augustenburger Platz 1, 13353 Berlin, Germany; ${ }^{15}$ Klinikum rechts der Isar der Technischen Universitaet, Frauen- und Poliklinik, Ismaninger Str. 22, 81675 Munich, Germany; ${ }^{16}$ Klinikum der Universitaet Muenchen, Campus Grosshadern, Klinik und Poliklinik fuer Frauenheilkunde und Geburtshilfe, Marchioninistr.15, 81377 Munich, Germany; ${ }^{17}$ Dr Horst Schmidt Klinik GmbH, Klinik fuer Gynaekologie und gynaekologische Onkologie, Ludwig-Erhard-Str. 100, 65199 Wiesbaden, Germany; ${ }^{18}$ Universitaetsklinikum Ulm, Frauenklinik, Prittwitzstrasse 43, 89075 Ulm, Germany; ${ }^{19}$ Universitaetsklinikum Schleswig-Holstein, Campus Kiel, Klinik fuer Gynaekologie und Geburtshilfe, Michaelisstrasse 16, 24105 Kiel, Germany; ${ }^{20}$ Universitaetsklinikum Tuebingen, Department fuer Frauengesundheit, Calwerstrasse 7, 72076 Tuebingen, Germany; ${ }^{21}$ Universitaetsklinikum Duesseldorf, Universitaetsfrauenklinik, Moorenstrasse 5, 40225 Duesseldorf, Germany; ${ }^{22}$ Evangelisches Krankenhaus, Frauenklinik, Kirchfeldstrasse 40, 40217 Duesseldorf, Germany; ${ }^{23}$ Medizinische Hochschule Hannover, Frauenklinik, Carl-Neuberg-Str. 1, 30625 Hannover, Germany; ${ }^{24}$ Klinikum der J.W. Goethe-Universitaet, Zentrum fuer Frauenheilkunde und Geburtshilfe, Theodor-Stern-Kai 7, 60590 Frankfurt am Main, Germany; ${ }^{25}$ Universitaetsklinikum Schleswig-Holstein, Campus Luebeck, Klinik fuer Gynaekologie und Geburtshilfe, Ratzeburger Allee 160,23562 Luebeck, Germany; ${ }^{26}$ Universitaetsklinikum Freiburg, Frauenklinik, Hugstetter Str. 55, 79106 Freiburg im Breisgau, Germany; ${ }^{27}$ Universitaetsklinikum Halle (Saale), Universitaetsklinik und Poliklinik fuer Gynaekologie, Ernst-Grube-Str. 40, 06120 Halle (Saale), Germany; ${ }^{28}$ Georg-August-Universitaet Goettingen, Gynaekologie und Geburtshilfe, Robert-Koch-Str. 40, 37075 Goettingen, Germany; ${ }^{29}$ Universitaetsklinikum Essen, Klinik fuer Frauenheilkunde und Geburtshilfe, Essen, Germany; ${ }^{30}$ Institut fuer Pathologie, Referenzzentrum fuer Gynaekopathologie, A2,2, 68159 Mannheim, Germany; ${ }^{31}$ Institut fuer Pathologie Trier-Dueren-Duesseldorf, Roonstrasse 30,52351 Dueren, Germany and ${ }^{32}$ Kliniken Essen-Mitte, Klinik fuer Gynaekologische Onkologie, Henricistrasse 92, 45136 Essen, Germany

*Correspondence: Dr S Mahner; E-mail: s.mahner@uke.de

${ }^{33}$ These authors contributed equally to this work.

Received 1 September 2014; revised 27 November 2014; accepted 6 December 2014; published online 6 January 2015 (c) 2015 Cancer Research UK. All rights reserved 0007-0920/15 
Background: Incomplete surgical staging is a negative prognostic factor for patients with borderline ovarian tumours (BOT). However, little is known about the prognostic impact of each individual staging procedure.

Methods: Clinical parameters of 950 patients with BOT (confirmed by central reference pathology) treated between 1998 and 2008 at 24 German AGO centres were analysed. In 559 patients with serous BOT and adequate ovarian surgery, further recommended staging procedures (omentectomy, peritoneal biopsies, cytology) were evaluated applying Cox regression models with respect to progression-free survival (PFS).

Results: For patients with one missing staging procedure, the hazard ratio (HR) for recurrence was 1.25 (95\%-Cl 0.66-2.39; $P=0.497)$. This risk increased with each additional procedure skipped reaching statistical significance in case of two (HR 1.95; $95 \%-\mathrm{Cl} 1.06-3.58 ; P=0.031)$ and three missing steps (HR 2.37; 95\%-Cl 1.22-4.64; $P=0.011)$. The most crucial procedure was omentectomy which retained a statistically significant impact on PFS in multiple analysis (HR $1.91 ; 95 \%-C l 1.15-3.19 ; P=0.013)$ adjusting for previously established prognostic factors as FIGO stage, tumour residuals, and fertility preservation.

Conclusion: Individual surgical staging procedures contribute to the prognosis for patients with serous BOT. In this analysis, recurrence risk increased with each skipped surgical step. This should be considered when re-staging procedures following incomplete primary surgery are discussed.

Preoperative diagnosis of borderline ovarian tumours (BOT) is frequently hindered by unspecific clinical symptoms and absence of appropriate diagnostic tools (Fischerova et al, 2012; Tang et al, 2012; Trillsch et al, 2013). As intraoperative fresh frozen section is of limited value for diagnosing BOT and informed consent for further operative procedures is not always obtained preoperatively, the primary surgical approach for BOT patients frequently results in incomplete surgical staging leading to formal indication of restaging surgery (Trillsch et al, 2010; Shih et al, 2011; Song et al, 2011).

Although incomplete surgical staging has been recently confirmed to be an independent negative prognostic factor for disease recurrence besides higher FIGO stage, residual tumour, and fertility preservation in the large cohort study on BOT of the Arbeitsgemeinschaft Gynaekologische Onkologie (AGO ROBOT study) (du Bois et al, 2013), little is known about the prognostic impact of each individual staging procedure. This information is, however, of high importance when counselling BOT patients after incomplete surgical staging. As most studies concentrate on the question whether fertility preservation is safe and feasible from an oncologic standpoint (Morice et al, 2001; Fauvet et al, 2005; Palomba et al, 2010; Trillsch et al, 2014; Uzan et al, 2014), the evidence for further recommended staging procedures as omentectomy, peritoneal biopsies, and cytology is sparse.

In the present study, we analysed the impact of each individual staging procedure on prognosis of patients with serous BOT within the large cohort of the AGO ROBOT study.

\section{MATERIALS AND METHODS}

Patients. Consecutive patients with primary diagnosis of BOT between 1998 and 2008 from 24 participating member institutions of the AGO study group were included in the multicentre ROBOT study (du Bois et al, 2013). Patient cases eligible for study inclusion were identified retrospectively by local investigators at each centre. Clinical data were then retrieved from hospital records and/or clinical tumour registries. Patients without available paraffinembedded material or with coincident invasive cancer were excluded. The prospective part of this study included an active follow-up and an independent central pathology review by expert gynaecopathologists (FK and $\mathrm{SH}$ ) strictly following current WHO diagnostic criteria (Tavassoli and Devilee, 2003). If upon pathologic review, a clinically relevant diagnostic discrepancy was revealed, the alternative review diagnosis was suggested and discussed with the local pathologist. Only cases with a finally confirmed diagnosis of BOT were included in the present analysis. For the active follow-up, patients were followed regarding their clinical outcome.

Owing to low event numbers in mucinous BOT (10 recurrences in 268 patients) and very low numbers of cases for endometroid $(n=10)$ or miscellaneous histology $(n=39)$, significance of prognostic factors for these histological subtypes could not be estimated reasonably. Therefore, the current analysis focused solely on patients with serous BOT.

Therapeutic strategies were documented according to patients' charts and surgery reports and aligned with pathology reports. Staging quality was considered adequate following German guidelines (Wagner et al, 2013), if the following procedures were performed: bilateral salpingo-oophorectomy for patients $\geqslant 55$ years or for younger patients without attempted organ preservation, omentectomy or omental biopsy, peritoneal biopsies, and peritoneal cytology. Neither removal of the uterus nor lymphadenectomy were regarded necessary parts of staging procedures. As complete omentectomy is standard in most of the participating institutions, the term 'omentectomy' is used for 'omentectomy and omental biopsy' throughout the manuscript. It was assumed that fertility-sparing surgery had been intended in patients who were younger than 55 years at diagnosis and had the uterus and at least parts of one ovary left after operation. For patients with fertility preservation, surgical staging was considered comprehensive when apart from the reproductive organs the same surgical steps as described above had been carried out. To achieve a homogenous study cohort for this subanalysis and to reduce the possible bias of preserved ovarian tissue, only patients with adequate ovarian surgery (either bilateral salpingo-oophorectomy or intended fertility preserving surgery in patients $<55$ years as described above) were considered for analysis. The study protocol was approved by local ethics committees at each participating centre.

Statistical analysis. All statistical analyses were conducted using IBM SPSS Statistics 19 and R 2.15.2 (R Foundation for Statistical Computing, Vienna, Austria). $P$ values $<0.05$ were considered statistically significant.

Clinicopathological variables and treatment parameters were compared by applying Student's $t$ test or chi square test, as appropriate. Kaplan-Meier estimates and log-rank test were used to illustrate and compare progression-free survival. For adjusted analysis regarding progression-free survival, Cox regression models were evaluated and presented via forest plots. In these analyses, staging procedures with suspected prognostic impact 
from unadjusted analysis were tested for independence adjusting for previously described prognostic factors (FIGO stage, fertility preservation, and postoperative residual tumour). Owing to excellent disease-specific and overall survival with low event numbers, these endpoints were not considered for adjusted analysis.

\section{RESULTS}

A total of 559 patients with confirmed diagnosis of serous BOT after central pathological review and a median age of 49 (14-92) years met the inclusion criteria. Detailed clinical and treatmentrelated parameters are provided in Table 1.

The majority of patients were diagnosed in FIGO stage I (73.9\%) with laparotomy as primary surgical approach in more than half of the patients $(54.9 \%)$. Staging quality after primary surgery was inadequate in 395 patients $(70.7 \%)$. This number was reduced to 281 patients $(50.3 \%)$ when patients with re-staging surgeries were considered as well. A total of 131 patients $(23.4 \%)$ were diagnosed with peritoneal implants, of which 21 (16.0\%) showed to be invasive. Re-staging surgery led to upstaging in 29 of the 199 patients undergoing this procedure (14.6\%). Of these 29 patients, $23(79.3 \%)$ had positive peritoneal implants (20 with non-invasive histology, four with invasive histology, one patient with both). The remaining six patients $(20.7 \%)$ were up-staged because of positive cytology or further adnexal involvement of the BOT.

Five-year-recurrence rate of the total cohort was 5.6\%, 13 of 53 patients $(24.5 \%)$ with recurrent disease experienced malignant transformation. In terms of the investigated staging procedures, omentectomy was carried out in $78.4 \%$, peritoneal biopsies in $66.9 \%$, and cytology in $68.3 \%$ of all patients (Table 1 ).

Each of the latter staging procedures, if not carried out, had a negative impact on progression-free survival in single, unadjusted analysis (omentectomy hazard ratio (HR) 2.00, $P=0.004$; peritoneal biopsies HR 1.51, $P=0.087$; cytology $\operatorname{HR} 1.63$, $P=0.041$, Table 2). This effect remained statistically significant for omentectomy in multiple analysis (HR 1.81; 95\%-CI 1.03-3.21; $P=0.041$, Table 2).

Consequently, the prognostic effect of an omitted omentectomy was tested for independence in a multiple analysis adjusting for previously described prognostic factors for BOT (Figure 1). In this Cox regression model, a prognostic impact could be confirmed for higher FIGO stage (FIGO II vs I; HR 2.35; 95\%-CI 1.29-4.30, $P=0.005$; FIGO III $v s$ I HR 2.89; 95\%-CI 1.58-5.27; $P=0.001$ ), fertility preservation (HR 3.28, 95\%-CI 2.03-5.28; $P<0.001$ ), incomplete surgical cytoreduction (HR 3.99; 95\%-CI 1.58-10.05; $P=0.003$ ), and also for omitted omentectomy (HR 1.91; 95\%-CI $1.15-3.19 ; P=0.013$, Figure 1$)$.

Patients undergoing omentectomy $(n=438,78.4 \%)$ were diagnosed in higher FIGO stages compared with patients without omentectomy $(n=121,21.6 \%$; FIGO stage > I $29.5 \%$ vs $15.0 \%$, $P<0.001$, Table 3$)$ and presented with higher rates of peritoneal implants $(26.7 \%$ vs $11.6, P=0.001)$ but had a lower 5-yearrecurrence rate $(10.7 \%$ vs $20.1 \%, P=0.004)$. Patients undergoing omentectomy were slightly younger ( $48 v s 53$ years, $P=0.192$ ), but a fertility-preserving approach was performed significantly less frequently in these patients $(16.0 \%$ vs $33.1 \%, P<0.001)$. In patients with omentectomy, bilateral salpingo-oophorectomy $(84.2 \%$ vs $66.9 \%, P<0.001)$, hysterectomy $(76.7 \%$ vs $51.2 \%, P<0.001)$ and the other two recommended staging procedures peritoneal biopsies $(78.5 \%$ vs $24.8 \%, P<0.001)$ and cytology $(74.4 \%$ vs $46.3 \%$, $P<0.001)$ were carried out significantly more frequently than in patients without omentectomy. Accordingly, appendectomy $(34.5 \%$ vs $11.6 \%, P<0.001)$ and pelvic $(23.5 \%$ vs $12.4 \%$, $P=0.005)$ or para-aortic lymph node dissection $(16.0 \%$ vs $5.8 \%$,
Table 1. Clinical patient characteristics, $n=559$

Age at first diagnosis

\begin{tabular}{|l|c}
\hline Median, years & 49 \\
Range & (14-92)
\end{tabular}

\section{FIGO stage}

IA/B

IC

$\| A-C$

IIIA-C

$279(49.9 \%)$

$134(24.0 \%)$

$65(11.6 \%)$

$81(14.5 \%)$

Primary surgical approach

Laparoscopy

Converted laparoscopy

Laparotomy

$198(35.4 \%)$

$54(9.7 \%)$

$307(54.9 \%)$

\section{Histologic characteristics}

Stromal microinvasion

Micropapillary pattern

$30(5.4 \%)$

$85(15.2 \%)$

Surgical procedures in primary and re-staging surgery ${ }^{a}$

Bilateral salpingo-oophorectomy

Unilateral salpingo-oophorectomy

Cystectomy

Hysterectomy

Omentectomy

Peritoneal biopsies

Cytology

Appendectomy

Pelvic LND/LN biopsies

Para-aortic LND/LN biopsies

$450(80.5 \%)$

$135(24.2 \%)$

$103(18.4 \%)$

$398(71.2 \%)$

$438(78.4 \%)$

$374(66.9 \%)$

$382(68.3 \%)$

$165(29.5 \%)$

$118(21.1 \%)$

$77(13.8 \%)$

\section{Peritoneal implants in primary or re-staging surgery}

None

$428(76.6 \%)$

Invasive

$110(19.7 \%)$

$21(3.8 \%)$

\section{Surgical cytoreduction}

\begin{tabular}{|l|c|}
\hline Complete & $517(92.5 \%)$ \\
Incomplete & $8(1.4 \%)$ \\
Unknown & $34(6.1 \%)$
\end{tabular}

Staging quality after primary surgery

\begin{tabular}{|l|l|}
\hline Adequate & $164(29.3 \%)$ \\
Inadequate & $395(70.7 \%)$
\end{tabular}

Staging quality after primary and re-staging surgery

\begin{tabular}{|l|l}
\hline Adequate & $278(49.7 \%)$ \\
Inadequate & $281(50.3 \%)$
\end{tabular}

Fertility-sparing surgery

\begin{tabular}{|l|l|}
\hline Yes & $110(19.7 \%)$ \\
No & $449(80.3 \%)$
\end{tabular}

Up-staging after re-staging surgery

Yes

No

$29(5.2 \%)$

$530(94.8 \%)$

\section{Recurrent disease}

Yes

Borderline tumour

High grade carcinoma

Low grade carcinoma

Unknown

No

$53(9.5 \%)$

$40 / 53(75.5 \%)$

$4 / 53(7.5 \%)$

$8 / 53(15.1 \%)$

$1 / 53(1.9 \%)$

$506(90.5 \%)$

\section{Site of recurrent disease}

\begin{tabular}{|c|c|}
\hline Ovarian tissue & $26 / 53(49.1 \%)$ \\
Ipsilateral & $9 / 53(17.0 \%)$
\end{tabular}

Contralatera

Peritoneum

$9 / 53(17.0 \%)$

$20 / 53(37.7 \%)$

Omentum

Other

Unknown

$1 / 53(1.9 \%)$

$2 / 53(3.8 \%)$

$10 / 53(18.9 \%)$

Malignant transformation during follow-up

Yes

No

5-year progression-free survival

$13 / 53(24.5 \%)$

$40 / 53(75.5 \%)$

\begin{tabular}{l|l}
5 -year disease-specific survival & $99.2 \%$
\end{tabular}

Abbreviations: $\mathrm{FIGO}=$ International Federation of Gynecology and Obstetrics;

$L N D=$ lymph node dissection; $L N=$ lymph node.

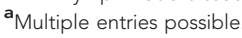


Table 2. Prognostic impact of staging procedures regarding PFS

\begin{tabular}{|c|c|c|c|c|c|c|c|c|}
\hline \multirow{3}{*}{$\begin{array}{c}\text { Omentectomy } \\
\text { no vs yes }\end{array}$} & \multicolumn{4}{|c|}{ Single analysis of individual staging procedures } & \multicolumn{4}{|c|}{ Multiple analysis of individual staging procedure } \\
\hline & \multirow{2}{*}{$\begin{array}{l}\text { HR } \\
2.00\end{array}$} & \multicolumn{2}{|c|}{$95 \% \mathrm{Cl}$} & \multirow{2}{*}{$\begin{array}{c}P \\
0.004\end{array}$} & \multirow{2}{*}{$\begin{array}{l}\text { HR } \\
1.81\end{array}$} & \multicolumn{2}{|c|}{$95 \% \mathrm{Cl}$} & \multirow{2}{*}{$\begin{array}{c}P \\
0.041\end{array}$} \\
\hline & & 1.24 & 3.21 & & & 1.03 & 3.21 & \\
\hline $\begin{array}{l}\text { Peritoneal biopsy } \\
\text { no vs yes }\end{array}$ & 1.51 & 0.94 & 2.40 & 0.087 & 1.01 & 0.57 & 1.78 & 0.986 \\
\hline $\begin{array}{l}\text { Cytology } \\
\text { no vs yes }\end{array}$ & 1.63 & 1.02 & 2.60 & 0.041 & 1.40 & 0.85 & 2.31 & 0.190 \\
\hline
\end{tabular}

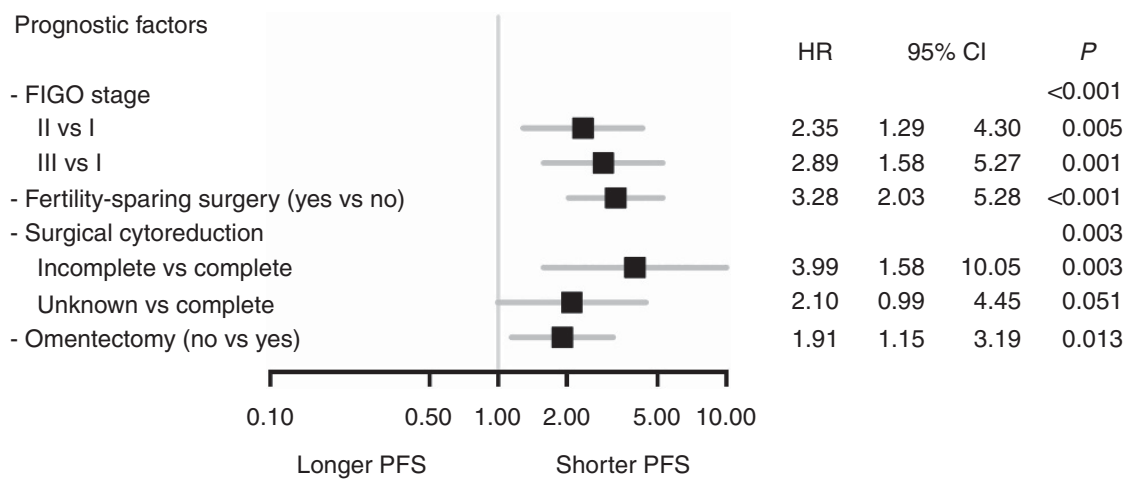

Figure 1. Adjusted analysis of prognostic factors regarding progression-free survival (PFS). Forest plot illustrating the multiple analysis adjusted for established prognostic factors together with omentectomy regarding their statistical significance and independence in terms of PFS by Cox regression model.

$P=0.002)$ were performed more frequently in patients with omentectomy. For $63.5 \%$ of patients with omentectomy, the surgical staging was assessed to be adequate after primary and restaging surgery.

To evaluate the influence of one or more omitted surgical steps of the recommended staging irrespective of their surgical nature, the prognostic impact of consecutively skipped staging procedures was tested (Figure 2A). For patients with one staging procedure missing, the HR for recurrence was 1.25 (95\%-CI 0.66-2.39; $P=0.497)$. This risk increased with each additionally skipped procedure reaching statistical significance in case of two (HR 1.95; 95\%-CI 1.06-3.58; $P=0.031$ ) or three missing steps (HR 2.37; 95\%-CI 1.22-4.64; $P=0.011$ ). Even when adjusted for previously described prognostic factors for BOT, the prognostic impact of two (HR 3.54; 95\%-CI 1.81-6.93, $P<0.001$ ) or three (HR 2.72; 95\%-CI $1.29-5.73, P=0.009)$ missing staging procedures remained statistically significant (Figure 2B).

\section{DISCUSSION}

The present analysis of the AGO ROBOT study attributes for the first time a prognostic importance to each individual step of surgical staging in the management of patients with serous BOT.

This information can help gynaecologic oncologists counselling patients with diagnosis of BOT and incomplete surgical staging following the primary approach. In this large dataset of 559 cases with confirmed diagnosis of serous BOT, $70.7 \%$ of the patients were inadequately staged during primary surgery and consequently candidates to be counselled for further management. This fraction is in accordance with other studies reporting rates of $61.3-70.3 \%$ of patients who formally require re-staging procedures to be comprehensively staged according to current guidelines (Fauvet et al, 2004; Ewald-Riegler et al, 2012; Azuar et al, 2013).

Apart from treatment recommendations for the reproductive organs including fertility-preserving aspects, the rationale for further recommended surgical staging procedures as omentectomy, peritoneal biopsies, and cytology is less evident. In this analysis, we could demonstrate that the recurrence risk of patients with serous BOT increased with each skipped step of the surgical staging. This expands the general results of previous studies indicating a clearly worse prognostic outcome of inadequately staged patients (Fauvet et al, 2004; Azuar et al, 2013; du Bois et al, 2013; Romeo et al, 2013).

Studies focusing on distinct surgical procedures are mainly available for the question of fertility preservation indicating higher recurrence rates for this approach (Palomba et al, 2010; Trillsch et al, 2014; Uzan et al, 2014). In this context, it has been shown that preservation of the primarily affected ovary raises the recurrence risk the most so that organ preservation should be reserved only for special constellations when the contralateral ovary had already been removed for other reasons or in case of bilateral disease (Fauvet et al, 2004; Palomba et al, 2010; du Bois et al, 2013; Uzan et al, 2014). In contrast, this study investigated the prognostic significance of staging procedures not directly related to fertility preservation (omentectomy, peritoneal biopsies, cytology), demonstrating the highest prognostic impact for omentectomy in unadjusted analysis. Even in multiple analysis adjusted for previously confirmed prognostic factors such as FIGO stage, fertility preservation, and macroscopic tumour residuals, omentectomy retains its statistical significance for prognosis.

Compared with invasive ovarian cancer in which the omentum is frequently affected and large tumour burden is described as omental cake (Sehouli et al, 2009; Woelber et al, 2010), omental implants are rarely seen in BOT patients (Fotopoulou et al, 2010; 
Table 3. Clinical characteristics for patients with or without omentectomy

Clinical patient characteristics

No omentectomy

\section{Age at first diagnosis}

Median, years

Range

FIGO stage

$\mathrm{IA} / \mathrm{B}$

IC

$\| A-C$

IIIA-C

Surgical approach in primary and re-staging surgery

Laparoscopy

Laparotomy

$n=121(21.6 \%)$

Omentectomy

$n=438(78.4 \%)$

P-value

Surgical procedures in primary and re-staging surgery ${ }^{c}$

Bilateral salpingo-oophorectomy

Unilateral salpingo-oophorectomy

Cystectomy

Hysterectomy

Peritoneal biopsies

Cytology

Appendectomy

Pelvic LND/LN biopsies

Para-aortic LND/LN biopsies

Peritoneal implants in primary or re-staging surgery

None

Non-invasive

Invasive

Surgical cytoreduction

Complete

Incomplete

Unknown

Staging quality after primary and re-staging surgery

Adequate

Inadequate

Fertility-sparing surgery

Yes

No

Up-staging after re-staging surgery

Yes

No

Recurrent disease

Yes

Borderline tumour

High grade carcinoma

Low grade carcinoma

Unknown

No

\begin{tabular}{|c|r}
\hline & $81(66.9 \%)$
\end{tabular}

$29(24.0 \%)$

$27(22.3 \%)$

$62(51.2 \%)$

$30(24.8 \%)$

$56(46.3 \%)$

$14(11.6 \%)$

$15(12.4 \%)$

7 (5.8\%)

48

48
$(14-86)$

$0.192^{a}$

$(16-92)$

$81(67.0 \%)$

$14(11.6 \%)$

$111(25.3 \%)$

$51(11.7 \%)$

$78(17.8 \%)$

$43(9.8 \%)$

395 (90.2\%)

$<0.001^{\text {b }}$

$3(2.5 \%)$

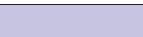

\section{Site of recurrent disease ${ }^{c}$}

\begin{tabular}{|c|c|c|c|}
\hline $\begin{array}{l}\text { Ovarian tissue } \\
\text { Ipsilateral } \\
\text { Contralateral } \\
\text { Peritoneum } \\
\text { Omentum } \\
\text { Other } \\
\text { Unknown }\end{array}$ & $\begin{array}{c}8 / 18(44.4 \%) \\
4 / 18(22.2 \%) \\
4 / 18(22.2 \%) \\
5 / 18(27.8 \%) \\
1 / 18(5.6 \%) \\
0 / 18(0.0 \%) \\
5 / 18(27.8 \%)\end{array}$ & $\begin{array}{c}18 / 35(51.4 \%) \\
5 / 35(14.3 \%) \\
16 / 35(45.7 \%) \\
23 / 35(65.7 \%) \\
0 / 35(0.0 \%) \\
2 / 35(5.8 \%) \\
5 / 35(14.3 \%)\end{array}$ & \\
\hline 5-year progression-free survival & $79.9 \%$ & $89.3 \%$ & $0.004^{d}$ \\
\hline 5-year disease-specific survival & $98.8 \%$ & $99.7 \%$ & $0.893^{d}$ \\
\hline
\end{tabular}



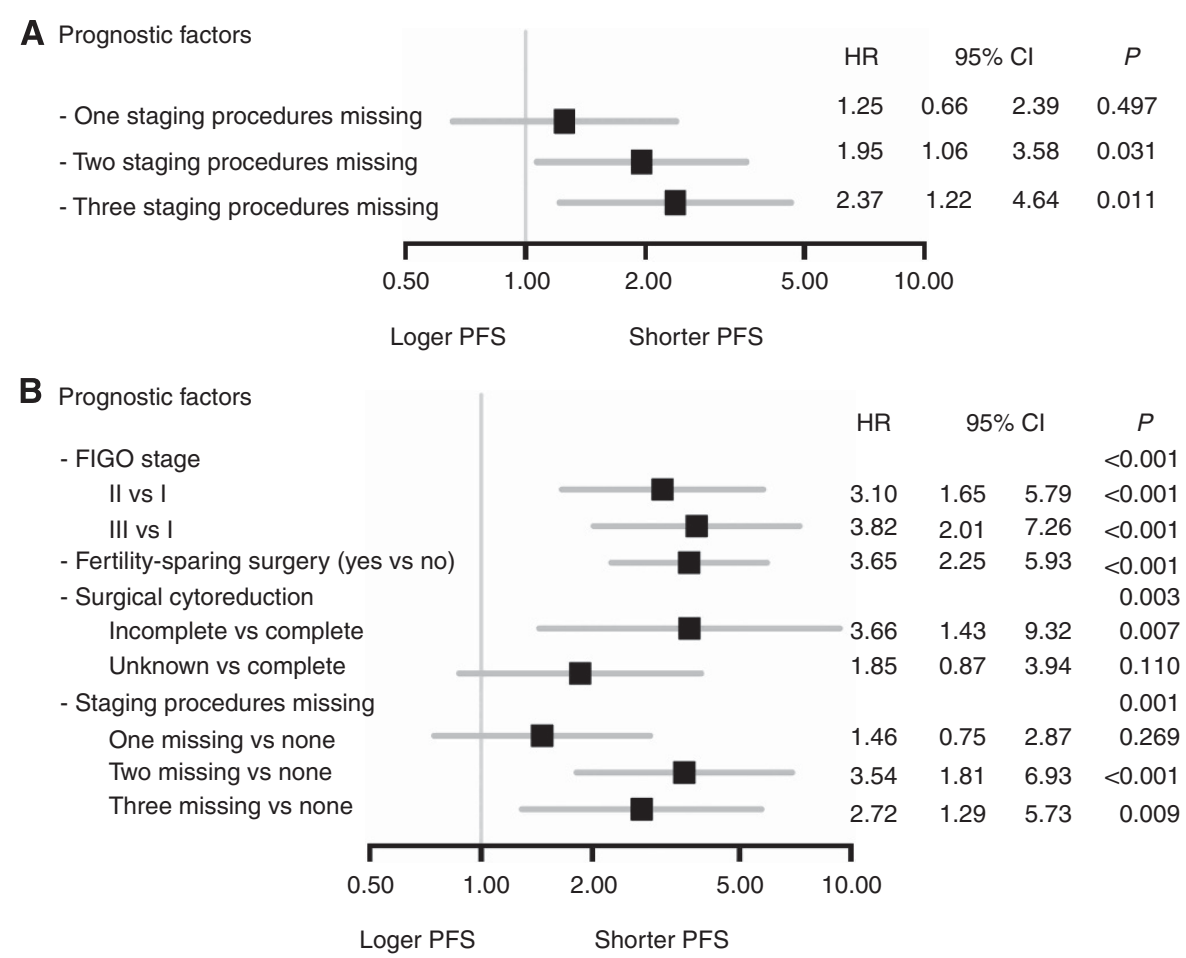

Figure 2. Analyses of missing staging procedures regarding progression-free survival (PFS). (A) Forest plot illustrating the unadjusted analysis of the prognostic impact of consecutively skipped staging procedures in terms of PFS by Cox regression model. (B) Forest plot for multiple analysis adjusted for established prognostic factors as well as for two and three missing surgical staging procedures in terms of PFS by Cox regression model.

Kristensen et al, 2014). With $73.9 \%$, the majority of all patients in the present cohort were diagnosed in FIGO stage I. Of all patients, $23.5 \%$ had implants that were of invasive histology in 21 patients (3.8\%). Of note, patients undergoing omentectomy had a significantly better prognosis despite a shift towards higher FIGO stage and more invasive implants. Conversely, for patients without omentectomy, fertility-preserving strategy was more frequently followed and other staging procedures less frequently performed which might also influence prognosis. Multiple analyses adjusted for these characteristics, however, underline that the removal of potentially affected structures like the omentum might impact prognosis and help to prevent relapse. Although the numbers of invasive recurrences in BOT patients are usually too small to significantly affect overall survival, it has to be noted that $24.5 \%$ of all patients with recurrent disease were diagnosed with malignant transformation resulting in a life-threatening condition with a consecutive indication for additional radical surgery and subsequent chemotherapy.

In our cohort, only $14.6 \%$ of 199 patients undergoing re-staging surgery were up-staged because of detection of extraovarian disease. For BOT, rates of up-staging between $14.7 \%$ and $47 \%$ have been reported and the indication for re-staging has been controversially discussed. Although some studies were able to show a positive effect on prognosis especially in case of early stage BOT (Fauvet et al, 2004; Azuar et al, 2013), other, often smaller analyses questioned the oncological value of this procedure (Land et al, 2002; Winter et al, 2002; Rao et al, 2004; Wingo et al, 2006; Zapardiel et al, 2010). In this context, the latter mainly concentrated on the question whether re-staging surgery leads to results which would change the future management of affected patients (e.g., additional chemotherapy in case of invasive implants). A correlation of re-staging surgery with the prognosis of the patients was not performed-in contrast to the present study.
The obvious limitation of our study is that patients were retrospectively included and patient cohorts were not randomly assigned to pre-defined staging procedures. Therefore, the results have to be cautiously interpreted to avoid possible selection bias. However, the AGO ROBOT dataset represents the so far largest dataset of BOT patients. The participating centres included all consecutive patients during the study period and all cases were subject to central pathological review resulting in a wellcharacterised cohort. As prospective investigations comparing different staging procedures will hardly ever be available, the present study might provide important new aspects to this question with immediate implications for clinical routine: In patients who underwent surgery with uni- or bilateral salpingooophorectomy without oncological intention due to unexpected diagnosis of serous BOT in a surgery for different reasons (e.g., appendectomy, Caesarean section, ovarian cyst), gynaecologic oncologists may now rather tend towards the recommendation of secondary surgery with re-staging procedures based on this analysis despite the generally excellent overall prognosis of BOT. Furthermore, the present data showing increasing risk of recurrence with each skipped staging procedure can help to illustrate treatment recommendations and facilitate informed consent with the patients.

\section{ACKNOWLEDGEMENTS}

The following additional collaborators contributed to this work: J.D. Ruetzel (Hamburg), P. Harter and O. du Bois (HSK Wiesbaden), C. Kurzeder (Ulm), J. Sehouli (Berlin), S. Avril (TU Muenchen), D. Mayr (LMU Muenchen), E. Kuehnle (Kiel), R. Rothmund (Tuebingen), M. Tjahadi (Hannover), S. Markert (Freiburg), C. Thomssen and C. Richter (Halle), U. Wagner 
(Marburg), W. Kuhn (Bonn), M. Peters (Solingen), G. Emons (Goettingen), R. Kimmig (Essen), and D. Schmidt (Mannheim). C. Nasemann (KKS Marburg) supported the data clarification process.

\section{CONFLICT OF INTEREST}

The authors have declared no conflicts of interest. No external funding sources were involved during this analysis.

\section{REFERENCES}

Azuar AS, Bourdel N, Ferrarrese G, Dauplat J, Mage G, Canis M (2013) Laparoscopic restaging of borderline ovarian tumours (BLOT): a retrospective study of 142 cases. Eur J Obstet Gynecol Reprod Biol 168(1): 87-91.

du Bois A, Ewald-Riegler N, de Gregorio N, Reuss A, Mahner S, Fotopoulou C, Kommoss F, Schmalfeldt B, Hilpert F, Fehm T, Burges A, Meier W, Hillemanns P, Hanker L, Hasenburg A, Strauss HG, Hellriegel M, Wimberger P, Keyver-Paik MD, Baumann K, Canzler U, Wollschlaeger K, Forner D, Pfisterer J, Schroder W, Munstedt K, Richter B, Kommoss S, Hauptmann S (2013) Borderline tumours of the ovary: A cohort study of the Arbeitsgmeinschaft Gynakologische Onkologie (AGO) Study Group. Eur J Cancer 49(8): 1905-1914.

Ewald-Riegler N, du Bois O, Fisseler-Eckhoff A, Kommoss F, Harter P, Traut A, Hils R, du Bois A (2012) Borderline tumors of the ovary: clinical course and prognostic factors. Onkologie 35(1-2): 28-33.

Fauvet R, Boccara J, Dufournet C, David-Montefiore E, Poncelet C, Darai E (2004) Restaging surgery for women with borderline ovarian tumors: results of a French multicenter study. Cancer 100(6): 1145-1151.

Fauvet R, Poncelet C, Boccara J, Descamps P, Fondrinier E, Darai E (2005) Fertility after conservative treatment for borderline ovarian tumors: a French multicenter study. Fertil Steril 83(2): 284-290quiz 525-6.

Fischerova D, Zikan M, Dundr P, Cibula D (2012) Diagnosis, treatment, and follow-up of borderline ovarian tumors. Oncologist 17(12): 1515-1533.

Fotopoulou C, Savvatis K, Braicu EI, Brink-Spalink V, Darb-Esfahani S, Lichtenegger W, Sehouli J (2010) Adult granulosa cell tumors of the ovary: tumor dissemination pattern at primary and recurrent situation, surgical outcome. Gynecol Oncol 119(2): 285-290.

Kristensen GS, Schledermann D, Mogensen O, Jochumsen KM (2014) The value of random biopsies, omentectomy, and hysterectomy in operations for borderline ovarian tumors. Int J Gynecol Cancer 24(5): 874-879.

Land R, Perrin L, Nicklin J (2002) Evaluation of restaging in clinical stage 1A low malignant potential ovarian tumours. Aust $N$ Z J Obstet Gynaecol 42(4): 379-382.

Morice P, Camatte S, El Hassan J, Pautier P, Duvillard P, Castaigne D (2001) Clinical outcomes and fertility after conservative treatment of ovarian borderline tumors. Fertil Steril 75(1): 92-96.

Palomba S, Falbo A, Del Negro S, Rocca M, Russo T, Cariati F, Annunziata G, Tolino A, Tagliaferri P, Zullo F (2010) Ultra-conservative fertility-sparing strategy for bilateral borderline ovarian tumours: an 11-year follow-up. Hum Reprod 25(8): 1966-1972.

Rao GG, Skinner E, Gehrig PA, Duska LR, Coleman RL, Schorge JO (2004) Surgical staging of ovarian low malignant potential tumors. Obstet Gynecol 104(2): 261-266.

Romeo M, Pons F, Barretina P, Radua J (2013) Incomplete staging surgery as a major predictor of relapse of borderline ovarian tumor. World J Surg Oncol 11: 13.

Sehouli J, Senyuva F, Fotopoulou C, Neumann U, Denkert C, Werner L, Gulten OO (2009) Intra-abdominal tumor dissemination pattern and surgical outcome in 214 patients with primary ovarian cancer. J Surg Oncol 99(7): 424-427.

Shih KK, Garg K, Soslow RA, Chi DS, Abu-Rustum NR, Barakat RR (2011) Accuracy of frozen section diagnosis of ovarian borderline tumor. Gynecol Oncol 123(3): 517-521.

Song T, Choi CH, Kim HJ, Kim MK, Kim TJ, Lee JW, Bae DS, Kim BG (2011) Accuracy of frozen section diagnosis of borderline ovarian tumors. Gynecol Oncol 122(1): 127-131.

Tang A, Kondalsamy-Chennakesavan S, Ngan H, Zusterzeel P, Quinn M, Carter J, Leung Y, Obermair A (2012) Prognostic value of elevated preoperative serum CA125 in ovarian tumors of low malignant potential: a multinational collaborative study (ANZGOG0801). Gynecol Oncol 126(1): $36-40$.

Tavassoli FA, Devilee P (2003) Pathology and genetics of tumours of the breast and female genital organs. IARC Press: Lyon.

Trillsch F, Mahner S, Ruetzel J, Harter P, Ewald-Riegler N, Jaenicke F, du Bois A (2010) Clinical management of borderline ovarian tumors. Exp Rev Anticancer Ther 10(7): 1115-1124.

Trillsch F, Mahner S, Woelber L, Vettorazzi E, Reuss A, Ewald-Riegler N, de Gregorio N, Fotopoulou C, Schmalfeldt B, Burges A, Hilpert F, Fehm T, Meier W, Hillemanns P, Hanker L, Hasenburg A, Strauss HG, Hellriegel M, Wimberger P, Baumann K, Keyver-Paik MD, Canzler U, Wollschlaeger K, Forner D, Pfisterer J, Schroeder W, Muenstedt K, Richter B, Kommoss F, Hauptmann S, du Bois A (2014) Age-dependent differences in borderline ovarian tumours (BOT) regarding clinical characteristics and outcome: results from a sub-analysis of the Arbeitsgemeinschaft Gynaekologische Onkologie (AGO) ROBOT study. Ann Oncol 25(7): 1320-1327.

Trillsch F, Ruetzel JD, Herwig U, Doerste U, Woelber L, Grimm D, Choschzick M, Jaenicke F, Mahner S (2013) Surgical management and perioperative morbidity of patients with primary borderline ovarian tumor (BOT). J Ovarian Res 6(1): 48.

Uzan C, Muller E, Kane A, Rey A, Gouy S, Bendiffallah S, Duvillard P, Fauvet R, Darai E, Morice P (2014) Prognostic factors for recurrence after conservative treatment in a series of 119 patients with stage I serous borderline tumors of the ovary. Ann Oncol 25(1): 166-171.

Wagner U, Harter P, Hilpert F, Mahner S, Reuss A, du Bois A, Petru E, Meier W, Ortner P, Konig K, Lindel K, Grab D, Piso P, Ortmann O, Runnebaum I, Pfisterer J, Luftner D, Frickhofen N, Grunwald F, Maier BO, Diebold J, Hauptmann S, Kommoss F, Emons G, Radeleff B, Gebhardt M, Arnold N, Calaminus G, Weisse I, Weis J, Sehouli J, Fink D, Burges A, Hasenburg A, Eggert C (2013) S3-Guideline on Diagnostics, Therapy and Follow-up of Malignant Ovarian Tumours: Short version 1.0 - AWMF registration number: 032/035OL. June 2013. Geburtshilfe Frauenheilkd 73(9): 874-889.

Wingo SN, Knowles LM, Carrick KS, Miller DS, Schorge JO (2006) Retrospective cohort study of surgical staging for ovarian low malignant potential tumors. Am J Obstet Gynecol 194(5): e20-e22.

Winter 3rd WE, Kucera PR, Rodgers W, McBroom JW, Olsen C, Maxwell GL (2002) Surgical staging in patients with ovarian tumors of low malignant potential. Obstet Gynecol 100(4): 671-676.

Woelber L, Jung S, Eulenburg C, Mueller V, Schwarz J, Jaenicke F, Mahner S (2010) Perioperative morbidity and outcome of secondary cytoreduction for recurrent epithelial ovarian cancer. Eur J Surg Oncol 36(6): 583-588.

Zapardiel I, Rosenberg P, Peiretti M, Zanagnolo V, Sanguineti F, Aletti G, Landoni F, Bocciolone L, Colombo N, Maggioni A (2010) The role of restaging borderline ovarian tumors: single institution experience and review of the literature. Gynecol Oncol 119(2): 274-277.

This work is published under the standard license to publish agreement. After 12 months the work will become freely available and the license terms will switch to a Creative Commons AttributionNonCommercial-Share Alike 4.0 Unported License. 